\title{
A Satisfaction Evaluation Method for Scenic Spot based on Linguistic Weighted Arithmetic Average Operator
}

\author{
Mingming Hu${ }^{1}$, Peiyu Ren ${ }^{1, *}$, Maozhu Jin ${ }^{1}$, Jibin Lan $^{2}$ and Yuyan Luo ${ }^{1}$ \\ ${ }^{1}$ Business School, Sichuan University, Chengdu 610064, China \\ ${ }^{2}$ College of Mathematics and Information Science, Guangxi University, Nanning 530004, China
}

Received: 7 Mar. 2013, Revised: 10 Jul. 2013, Accepted: 11 Jul. 2013

Published online: 1 Nov. 2013

\begin{abstract}
Based on the level empowerment system and the linguistic operator, a satisfaction evaluation process is proposed in this paper. First of all, a level empowerment system is established to generate the weight of each surveyed tourist. Then, some new linguistic operations are defined which can remedy the defects of the existed operations. Besides, the expectation and variance in linguistic information environment are defined to generate the weight of each character of tourist and the weights of indicators, and linguistic weighted arithmetic average ( $L W A A)$ operator is introduced to aggregate the linguistic information of each tourist and the group linguistic information of each indicator. Finally, a satisfaction evaluation case is illustrated to explain the evaluation process.
\end{abstract}

Keywords: Satisfaction evaluation; level empowerment system; linguistic information; linguistic weighted arithmetic average $(L W A A)$ operator.

\section{Introduction}

Tourist industry is developing rapidly in China, the number of tourists is increasing from 744 million in the year 2000 to 2103 million in the year 2010 which is about 2.8 times than the year 2000. It is the primary source of national revenue. To promote the development of national economic, tourist satisfaction has been studied since 1960s [1] to improve the scenic spot and attract more tourists. Not only is the research of tourist satisfaction important for management, but it is also viewed as a meaningful topic in academics. In the past five decades, tourists' satisfaction research has led to the efforts to discuss the satisfaction index, comparatively study the satisfaction of two groups of tourists and analyse the consequences of satisfaction evaluation results [2-17]. For example, Pizam et al. [7] studied the social relationship between hosts and tourists by 388 tourists and found that the more favorable the tourists' feelings towards their hosts were, the more positive changes in attitudes towards hosts and the destination were. Furthermore, it was found that the higher the intensity of social relationship between hosts and tourists was, the higher the satisfaction of these tourists with their stay and experience was. Nield et al. [8] studied the role of food in satisfaction through the investigation carried out amongst 341 respondents and found that food service was an important contributor to tourist satisfaction. Kozak [9] studied the differences between satisfaction levels of two nationalities' persons who visited the same destination and found that British tourists were more likely to be satisfied with almost all individual attributes than German tourists. Yu et al. [10] comparatively analyzed the international tourist satisfaction of their travel experience with tourist attractions, facilities, services and prices in Mongolia. Hui et al. [11] studied tourist satisfaction in Singapore and found that price was insignificant in shaping overall satisfaction levels for all groups of tourists. Chi et al. [12] studied the structural relationships of destination image, tourist satisfaction and destination loyalty and found that : (1) destination image directly influenced attribute satisfaction; (2) destination image and attribute satisfaction were both direct antecedents of overall satisfaction; and (3) overall satisfaction and attribute satisfaction in turn had direct and positive impact on destination loyalty. Alegre et al. [13] examined the impact of the satisfaction and dissatisfaction on both overall tourist satisfaction and their intention to return to the destination. Lee et al. [14] examined the causal

\footnotetext{
*Corresponding author e-mail: renpy.scu@163.com
} 
relationship among tourist expectations, tourist motivations, tour quality, tourist satisfaction, tourist complaints and tourist loyalty of Chinese tourists in the Republic of Korea using path analysis. Torres-Sovero [15] analyzed the factors affecting tourist satisfaction and found that the quality of accommodation was the factor that had the largest influence on overall satisfaction. Mikulic [16] explored asymmetric effects in tourist satisfaction by using dummy regression. Song [17] developed an assessment system of tourist satisfaction based on a dual-model framework and demonstrated its general applicability.

However, almost all these studies of tourist satisfaction are based on an investigation, which uses a five-point scale [18] to express evaluation information, that's to say, 1 stands for poor, 3 stands for fair and 5 stands for excellent, and calculate the mean and variance. There are two defects in the way of dealing with the satisfaction information. The first defect is that the operation of the real number is not closed in the linguistic evaluation set. For example, if the first surveyed tourist evaluates the indicator to be excellent(5) and the second surveyed tourist evaluates the indicator to be fair(3), then the sum of the two surveyed tourists' evaluation information means $5+3=8$ and 8 has jumped out of the five-point scale. The second defect is that the evaluation doesn't affect the objective fact, which is because of the surveyed persons with different backgrounds. Different people evaluate the same objective fact, the results may be different. For example, a car running with the rate of $90 \mathrm{~km} / \mathrm{h}$ in the freeway, a driver may think that the rate of the car is fair, but a person who doesn't drive may think that it is fast. Conversely, different people evaluate the different objective facts, the results may be the same. For example, a driver may evaluate that the car driving in $120 \mathrm{~km} / \mathrm{h}$ is fast and a person who doesn't drive may evaluate that the car driving in $90 \mathrm{~km} / \mathrm{h}$ is fast. To avoid the problems in traditional evaluation process, linguistic variables, linguistic operations and a level empowerment method are introduced in the process of evaluation. This paper is arranged as follows. In Section 2, an evaluation indicators system of satisfaction and a level empowerment system are established. New operation rules of uncertain linguistic variables and the linguistic weighted arithmetic average $(L W A A)$ operator are introduced in Section 3. In Section 4, an evaluation case of Jiuzhai Valley is illustrated to explain the evaluation process. This paper is concluded in Section 5.

\section{The evaluation indicators system and a level empowerment system}

Both a reasonable evaluation indicators system of satisfaction and a scientific empowerment method are the foundation of an effective satisfaction evaluation. In this section, an evaluation indicators system will be established and a level empowerment system will be established to generate the weight of each decision maker.

\subsection{The indicators system}

A reasonable evaluation indicators system can keep the evaluation in comprehensiveness, objectivity and fairness. It also can help to find the reason of dissatisfaction, improve the touring environment, attract more tourists, and promote the development of tourism economy.

To evaluate tourist satisfaction, two-level indicators are taken into account. The indicators of first level is basic facility (B), management (M), services (SE), drinks and foods (D), accommodation (A), entertainment (E) and shopping ( $\mathrm{SH})$. And the indicators of second level can be listed as follows. Basic facility (B): trash bin of scenic spot (BT), washing room of scenic spot (BW), public facility for rest of scenic spot (BP), landmark and visual sign of scenic spot (BL), safety facility of scenic spot (BS); Management (M): ticket price of scenic spot (MTS), traffic price (MTP), sanitation of scenic spot (MS), degree of crowdedness (MD); Service (SE): ticket service (SET), guide service (SEG), consultation service (SEC), complaints handling (SEH); Drinks and foods (D): features of food (DF), convenience of drinks and foods (DC), sanitation of drinks and foods (DS), price of drinks and foods (DP); Accommodation (A): comfort of accommodation (AC), hygiene of accommodation (AH), price of accommodation (AP); Entertainment (E): category of entertainment (EC), amusement of entertainment (EA), safety of entertainment (ES), price of entertainment (EP); Shopping (SH): shopping settings (SHS), variety of souvenir (SHV), Feature of souvenir (SHF), price of souvenir (SHP). Two levels of evaluation indicators system are established and shown in Table 1, which is suitable for the characteristics of China's scenic spot.

After constructing the evaluation indicators system, the questionnaire survey method is used to study tourist satisfaction of scenic spot. 1034 tourists were investigated in Five A-level scenic spot Jiuzhai Valley. 833 tourists filled in questionnaires in Jiuzhai Valley. Screening out 737 questionnaires whose integrality is above $60 \%$ and summarizing all the questionnaires, the structure of the surveyed people is summarized in Table 2 and the data of the survey result in \{Very dissatisfaction (VD), Dissatisfaction (D), Fair (F), Satisfaction (S), Very dissatisfaction (VS) $\}$ of each indicator in Jiuzhai Valley is shown in Table 3.

From the percentage in Table 2, we can see that the number of male tourists is almost the same as female tourists. The age of the tourists mainly concentrates among 26-55 years old, and the young and the old occupy a very small part. Considering the education background 
of tourists, more than $80 \%$ tourists have accepted higher education. Besides, seeing from the occupation of the tourists, civil servants and enterprise personnel occupy a more than $60 \%$, individual and private owners, retiree, students occupy a very small part.

For the variety of the background of each surveyed people, a level empowerment system will be established to generate the weight of each surveyed people.

\subsection{The level empowerment system}

The character of each surveyed people is different from each other. Different surveyed people have different gender, age, background of education, occupation. The attitude of different gender, age, background of education and occupation toward the objective things may be different. For example, the views provided by a person above 55 years old is more true than a person under 19 years old.

Suppose, the weight of gender is $v_{1}$, the weight of age is $v_{2}$, the weight of education background is $v_{3}$, the weight of occupation is $v_{4}$, the values of $v_{1}, v_{2}, v_{3}, v_{4}$ is shown in Table 4, where $\sum_{j=1}^{2} v_{1 j}=1, \sum_{j=1}^{5} v_{2 j}$ $=1, \sum_{j=1}^{5} v_{3 j}=1, \sum_{j=1}^{6} v_{4 j}=1, \quad$ and $v_{i j}>0, i=1,2,3,4, j=1,2, \ldots, 6$.

The level empowerment system can be constructed in Figure 1 to generate the weight of each surveyed people. When the weight of each attribute is determined, the weight of each surveyed persons can be generated from Figure 1. The weight of $k$ th surveyed tourist can be calculated by

$$
w^{k}=v_{1} \cdot v_{2} \cdot v_{3} \cdot v_{4} .
$$

For example, if the $k$ th surveyed person is a female, between 19 and 25 years old, she has gotten the bachelor degree and works as a civil servant, then the weight of the $k$ th surveyed person is $w^{k}=v_{1} \cdot v_{2} \cdot v_{3} \cdot v_{4}=v_{12} \cdot v_{22} \cdot v_{34} \cdot v_{41}$.

In this section, a evaluation indicators system of satisfaction and a level empowerment system are established. The indicators system of satisfaction can help us to evaluate the satisfaction of tourists toward scenic spot objectively.

\section{The satisfaction evaluation model}

\subsection{New operation rules of uncertain linguistic variables in the extended linguistic scale}

Let $L=\left\{l_{j} \mid j=-t,-(t-1), \cdots, 0, \cdots, t-1, t\right\}$ be a finite and totally ordered discrete term set, where $l_{j}$ is a value of linguistic variable, $N$ is a set of natural numbers [19]. For example, in the survey of satisfaction, the surveyed people expresses his/her view by linguistic variable in the linguistic set \{Very satisfaction, Satisfaction, Fair, Dissatisfaction, Very dissatisfaction $\}$, then, a set of five terms $L$ could be

$L=\left\{l_{-2}=\right.$ Very dissatisfaction, $l_{-1}=$ Dissatisfaction, $l_{0}=$ Fair, $l_{1}=$ Satisfaction, $l_{2}=$ Very satisfaction $\}$, where $l_{i}<l_{j}$, if $i<j$.

Generally, the linguistic term set $L=\left\{l_{j} \mid-t,-(t-\right.$ $1), \ldots, 0, \ldots, t-1, t\}\left(t \in Z^{*}\right.$ and $\left.t \geq 1\right)$ should satisfy the following characteristics[20-22]:

(1)The set is ordered: $l_{i}<l_{j}$, if $i<j$;

(2)There exists the negation operator: $\operatorname{neg}\left(l_{i}\right)=l_{-i}$;

(3)Max operator: $\max \left\{l_{i}, l_{j}\right\}=l_{j}$, if $i \leq j$;

(4)Min operator: $\min \left\{l_{i}, l_{j}\right\}=l_{i}$, if $i \leq j$.

$L=\left\{l_{j} \mid j=-t,-(t-1), \cdots, 0, \cdots, t-1, t\right\}\left(t \in Z^{*}\right.$ and $t \geq 1)$ is a discrete term set. In order to aggregate all the linguistic decision information and avoid losing linguistic decision information, the discrete term set $L$ is extended to a continuous term set[23] $\bar{L}=\left\{\bar{l}_{\alpha} \mid-(t+1)<\alpha<(t+1), \alpha \in R\right\}\left(t \in Z^{*}\right.$ and $\left.t \geq 1\right)$ , where $\bar{l}_{-t}$ means the most dissatisfaction, $\bar{l}_{0}$ means fair and $\bar{l}_{t}$ means the most satisfaction. Obviously, $\bar{L}$ is extended from $L$, and the linguistic term $\bar{l}_{\alpha}(\alpha \in Z)$ in $\bar{L}$ is called the original linguistic term. Usually, the tourist uses the original linguistic term to evaluate the satisfaction.

The operations in $\bar{L}$ are defined by $\mathrm{Wu}$ and Chen [24] and $\mathrm{Xu}$ [25] as follows: suppose that any two linguistic terms $\bar{l}_{\alpha}, \bar{l}_{\beta} \in \bar{L}$ and $\lambda \in[0,1]$, then the basic addition and scalar multiplication operation are defined.

(1) $\bar{l}_{\alpha} \oplus \bar{l}_{\beta}=\bar{l}_{\alpha+\beta}$;

(2) $\lambda \bar{l}_{\alpha}=\bar{l}_{\lambda \alpha}$.

For any three linguistic terms $\bar{l}_{\alpha}, \bar{l}_{\beta}, \bar{l}_{\gamma} \in \bar{L}$ and $\lambda, \lambda_{1}, \lambda_{2}$ $\in[0,1]$, based on the addition and scalar multiplication, the following properties can be generated.

(1) $\bar{l}_{\alpha} \oplus \bar{l}_{\beta}=\bar{l}_{\beta} \oplus \bar{l}_{\alpha}$

(2) $\left(\bar{l}_{\alpha} \oplus \bar{l}_{\beta}\right) \oplus \bar{l}_{\gamma}=\bar{l}_{\alpha} \oplus\left(\bar{l}_{\beta} \oplus \bar{l}_{\gamma}\right)$;

(3) For any element $\bar{l}_{\alpha} \in \bar{L}$, there exists an element $\bar{l}_{0} \in$ $\bar{L}$, such that $\bar{l}_{\alpha} \oplus \bar{l}_{0}=\bar{l}_{\alpha}$;

(4) For any element $\bar{l}_{\alpha} \in \bar{L}$, there exists an element $\bar{l}_{-\alpha} \in \bar{L}$, such that $\bar{l}_{\alpha} \oplus \bar{l}_{-\alpha}=\bar{l}_{0}$;

(5) $1 \bar{l}_{\alpha}=\bar{l}_{\alpha}$;

(6) $\lambda_{1}\left(\lambda_{2} \bar{l}_{\alpha}\right)=\left(\lambda_{1} \lambda_{2}\right) \bar{l}_{\alpha}$;

(7) $\left(\lambda_{1}+\lambda_{2}\right) \bar{l}_{\alpha}=\lambda_{1} \bar{l}_{\alpha} \oplus \lambda_{2} \bar{l}_{\alpha}$;

(8) $\lambda\left(\bar{l}_{\alpha} \oplus \bar{l}_{\beta}\right)=\lambda \bar{l}_{\alpha} \oplus \lambda \bar{l}_{\beta}$.

However, the addition operation is not closed in the linguistic term set $\bar{L}$, since the addition of two linguistic terms may jump out of the linguistic term set $\bar{L}$. For example, $\bar{l}_{t} \in \bar{L}$, then $\bar{l}_{t} \oplus \bar{l}_{t}=\bar{l}_{2 t}$. For $t \geq 1$, then $\bar{l}_{2 t}=\bar{l}_{t+t} \geq \bar{l}_{t+1}$. So, $\bar{l}_{2 t} \notin \bar{L}$. Then, the properties (1-2) and (7-8) generated from the basic addition and scalar multiplication operation are unsatisfied. To avoid this defect, a new addition operation will be defined.

Definition 1 Let $\bar{L}$ be the extended continuous linguistic term set and $l_{\alpha} \in \bar{L}$, then the mapping value $g\left(l_{\alpha}\right)$ of $l_{\alpha}$ can be gotten by the following function: 
Table 1: The evaluation indicators system of scenic spot

\begin{tabular}{lll}
\hline & Indicators of first level & Indicators of second level \\
The evaluation indicators & Basic facility(B) & Trash bin of scenic spot(BT) \\
system of scenic spot & Washing room of scenic spot(BW) \\
& Public facility for rest of scenic spot(BR) \\
& Landmark and visual sign of scenic spot(BG) \\
& Sanety facility of scenic spot(BS) \\
& Ticket price of scenic spot(MTS) \\
& Traffic price(MTP) \\
& Sanitation of scenic spot(MS) \\
& Degree of crowdedness(MD) \\
& Ticket service(SES) \\
& Guide service(SEG) \\
& Consultation service(SEC) \\
& Complaints handling(SEH) \\
& Features of drinks and foods(DF) \\
& Convenience of drinks and foods(DC) \\
& Sanitation of drinks and foods(DS) \\
& Price of drinks and foods(DP) \\
Accommodation(A) & Comfort of accommodation(AC) \\
& Sanitation of accommodation(AS) \\
& Hygiene of accommodation(AH) \\
Entertainment(E) & Category of entertainment(EC) \\
& Amusement of entertainment(EF) \\
& Safety of entertainment(ES) \\
& Price of entertainment(EP) \\
Shopping(SH) & Shopping settings(SHS) \\
& Variety of souvenir(SHV) \\
& Features of souvenir(SHF) \\
& Price of souvenir(SHP) \\
&
\end{tabular}

Table 2: The structure of the surveyed people

\begin{tabular}{lclr}
\hline Category & \multicolumn{3}{c}{ Category } \\
\hline Gender(803) & & Age $(796)$ & $1.63 \%$ \\
Male & $45.45 \%$ & Under 19 years old & $17.21 \%$ \\
Female & $54.55 \%$ & $19-25$ years old & $37.06 \%$ \\
Occupation(785) & & $26-35$ years old & $35.43 \%$ \\
Civil servants & $28.66 \%$ & $36-55$ years old & $8.67 \%$ \\
The enterprise personnel & $36.05 \%$ & Above 55 years old \\
The individual and private owners & $12.10 \%$ & Background of education(779) & \\
Retiree & $8.41 \%$ & Junior high school and under & $2.44 \%$ \\
Students & $4.84 \%$ & Senior high school & $16.30 \%$ \\
Others & $9.94 \%$ & College graduate & $28.63 \%$ \\
& & Bachelor degree receivers & $45.57 \%$ \\
& & Master degree receivers and above & $7.06 \%$ \\
\hline
\end{tabular}

$g: \bar{L} \rightarrow(-\infty,+\infty)$,

$g\left(\bar{l}_{\alpha}\right)=\tan \frac{\pi \alpha}{2 t+2}, \bar{l}_{\alpha} \in \bar{L}$.

Definition 2 Let $\bar{L}$ be the extended continuous linguistic term set and $l_{\alpha} \in \bar{L}$, then the mapping value $g\left(l_{\alpha}\right)$ corresponding to the linguistic set $l_{\alpha}$ can be gotten by the following function:

$g^{-1}:(-\infty,+\infty) \rightarrow \bar{L}$,

$g^{-1}(x)=\bar{l}_{\alpha}$, where $\alpha=\frac{(2 t+2) \arctan x}{\pi}, x \in(-\infty,+\infty)$.

Based on the two functions $g\left(\bar{l}_{\alpha}\right)$ and $g^{-1}(x)$, the addition operation and scalar multiplication operation are defined as follows:
Definition 3 For any two linguistic terms $\bar{l}_{\alpha}, \bar{l}_{\beta} \in \bar{L}$, then

(1) $\bar{l}_{\alpha} \oplus \bar{l}_{\beta}=g^{-1}\left[g\left(\bar{l}_{\alpha}\right)+g\left(\bar{l}_{\beta}\right)\right]$;

(2) $\lambda \bar{l}_{\alpha}=g^{-1}\left[\lambda g\left(\bar{l}_{\alpha}\right)\right]$.

Example 1 Let $t=2$, for $\bar{l}_{0.5}, \bar{l}_{1.5}, \bar{l}_{1.7} \in \bar{L}$ and $9 \in R$, then

(1) $\bar{l}_{0.5} \oplus \bar{l}_{1.5}=g^{-1}\left[g\left(\bar{l}_{0.5}\right)+g\left(\bar{l}_{1.5}\right)\right]=g^{-1}\left[\tan \frac{0.5 \pi}{2 \times 2+2}+\right.$ $\left.\tan \frac{1.5 \pi}{2 \times 2+2}\right]=g^{-1}(1.2679)=\bar{l}_{1.7246}$;

(2) $9 \bar{l}_{1.7}=g^{-1}\left[9 g\left(\bar{l}_{1.7}\right)\right]=g^{-1}(11.1141)=\bar{l}_{2.8286}$.

Assume that $f(x)=\tan \left(\frac{\pi x}{2 t+2}\right):(-t-1, t+1) \rightarrow(-\infty,+\infty)$ is a strictly monotonous and continuous function which 
Table 3: The screened questionnaires data in Jiuzhai Valley

\begin{tabular}{lccccccccccccc}
\hline EI & VS & S & F & D & VD & Totality & EI & VS & S & F & D & VD & Totality \\
\hline BT & 234 & 365 & 113 & 15 & 3 & 730 & DC & 53 & 186 & 295 & 110 & 67 & 711 \\
BW & 210 & 336 & 147 & 28 & 9 & 730 & DS & 63 & 207 & 312 & 81 & 44 & 707 \\
BP & 167 & 332 & 177 & 50 & 9 & 735 & DP & 43 & 145 & 269 & 156 & 94 & 707 \\
BL & 188 & 368 & 145 & 15 & 12 & 728 & AC & 59 & 226 & 286 & 72 & 40 & 683 \\
BS & 184 & 368 & 153 & 16 & 8 & 729 & AH & 63 & 230 & 275 & 79 & 43 & 690 \\
MTS & 80 & 242 & 262 & 100 & 35 & 719 & AP & 50 & 197 & 299 & 84 & 37 & 667 \\
MTP & 98 & 254 & 251 & 87 & 23 & 713 & EC & 53 & 169 & 324 & 70 & 26 & 642 \\
MS & 368 & 331 & 30 & 3 & 4 & 736 & EA & 63 & 188 & 305 & 67 & 22 & 645 \\
MD & 52 & 197 & 175 & 157 & 94 & 675 & ES & 68 & 203 & 310 & 41 & 19 & 641 \\
SET & 105 & 328 & 208 & 31 & 13 & 685 & EP & 60 & 153 & 317 & 85 & 28 & 643 \\
SEG & 114 & 323 & 228 & 37 & 14 & 716 & SHS & 63 & 201 & 353 & 58 & 26 & 701 \\
SEC & 96 & 315 & 201 & 24 & 13 & 649 & SHV & 59 & 214 & 340 & 66 & 23 & 702 \\
SEH & 39 & 128 & 127 & 17 & 14 & 325 & SHF & 60 & 221 & 328 & 62 & 23 & 694 \\
DF & 48 & 157 & 291 & 134 & 74 & 704 & SHP & 51 & 193 & 302 & 113 & 38 & 697 \\
\hline
\end{tabular}

Table 4: The values of $v_{1}, v_{2}, v_{3}, v_{4}$

\begin{tabular}{llll}
\hline Category & Category & \\
\hline Gender $\left(v_{1}\right)$ & & Age $\left(v_{2}\right)$ & $v_{21}$ \\
Male & $v_{11}$ & Under 19 years old & $v_{22}$ \\
Female & $v_{12}$ & $19-25$ years old & $v_{23}$ \\
& & $26-35$ years old & $v_{24}$ \\
& & $36-55$ years old & $v_{25}$ \\
& & Above 55 years old & \\
Background of education $\left(v_{3}\right)$ & & Occupation $\left(v_{4}\right)$ & $v_{41}$ \\
Junior high school and under & $v_{31}$ & Civil servants & $v_{42}$ \\
Senior high school & $v_{32}$ & The enterprise personnel & $v_{43}$ \\
College graduates & $v_{33}$ & The individual and private owners & $v_{44}$ \\
Bachelor degree receivers & $v_{34}$ & Retiree & $v_{45}$ \\
Master degree receivers and above & $v_{35}$ & Students & \\
Others & $v_{46}$ & &
\end{tabular}

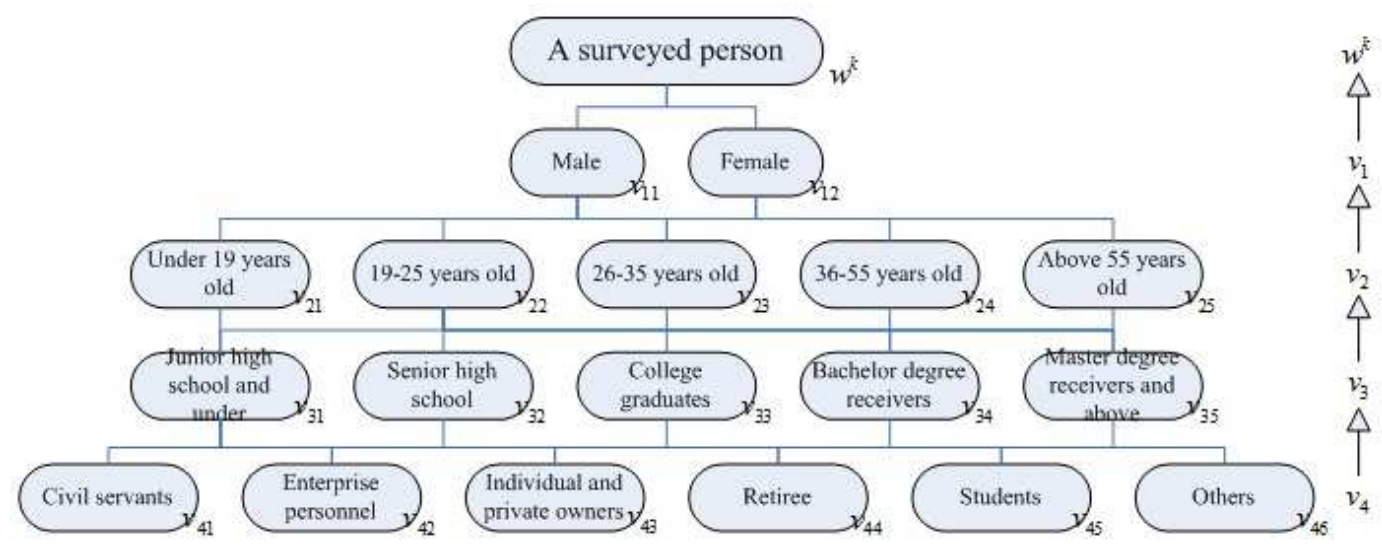

Figure 1. The level empowerment system

satisfies: $\lim _{x \rightarrow-t-1} f(x)=-\infty, \lim _{x \rightarrow t+1} f(x)=+\infty$, and $f(0)=0$. Then, $f(x)$ is a invertible function and $f^{-1}(x)=\frac{(2 t+2) \arctan (x)}{\pi}:(-\infty,+\infty) \rightarrow(-t-1, t+1)$ is a strictly mono-

tonous and continuous mapping which satisfies: $f^{-1}(0)=0, \quad \lim _{x \rightarrow-\infty} f^{-1}(x)=-t-1, \quad$ and $\lim _{x \rightarrow+\infty} f^{-1}(x)=t+1$. Let $t=5$, the graphics of both $f(x)$ and $f^{-1}(x)$ are shown in Figure 2.

Based on the two functions $f(x)$ and $f^{-1}(x)$, the addition operation and scalar multiplication operation have the following properties.

Property 1 For any two linguistic terms $\bar{l}_{\alpha}, \bar{l}_{\beta} \in \bar{L}$, then (1) $\bar{l}_{\alpha} \oplus \bar{l}_{\beta}=\bar{l}_{f^{-1}[f(\alpha)+f(\beta)]}$; 

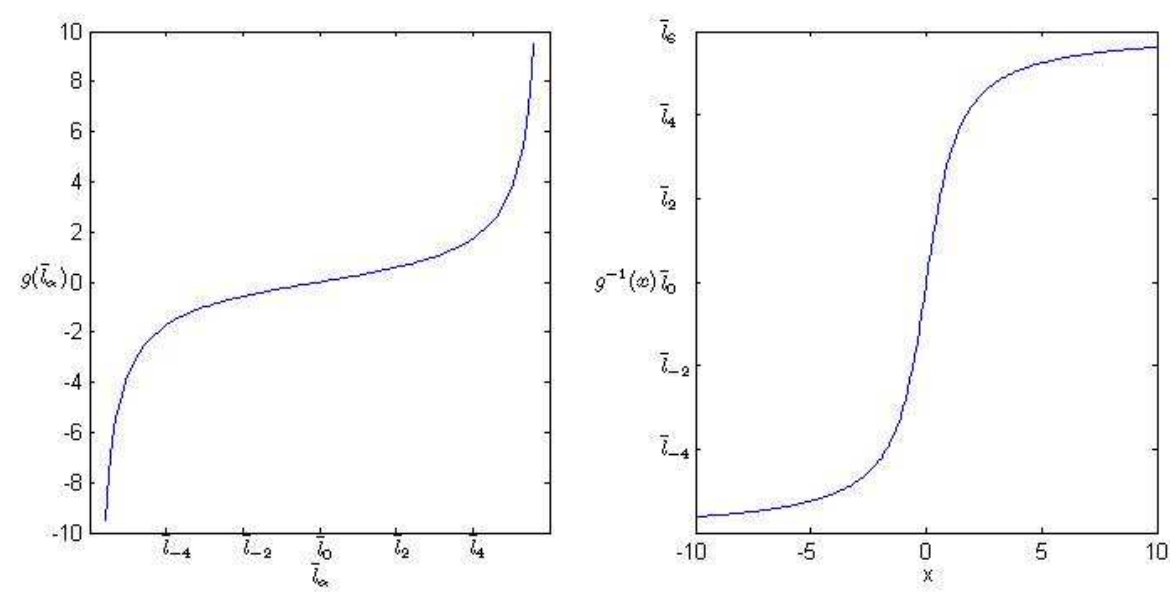

Figure 2. The graphic of $g\left(\bar{l}_{\alpha}\right)$ and $g^{-1}(x)$
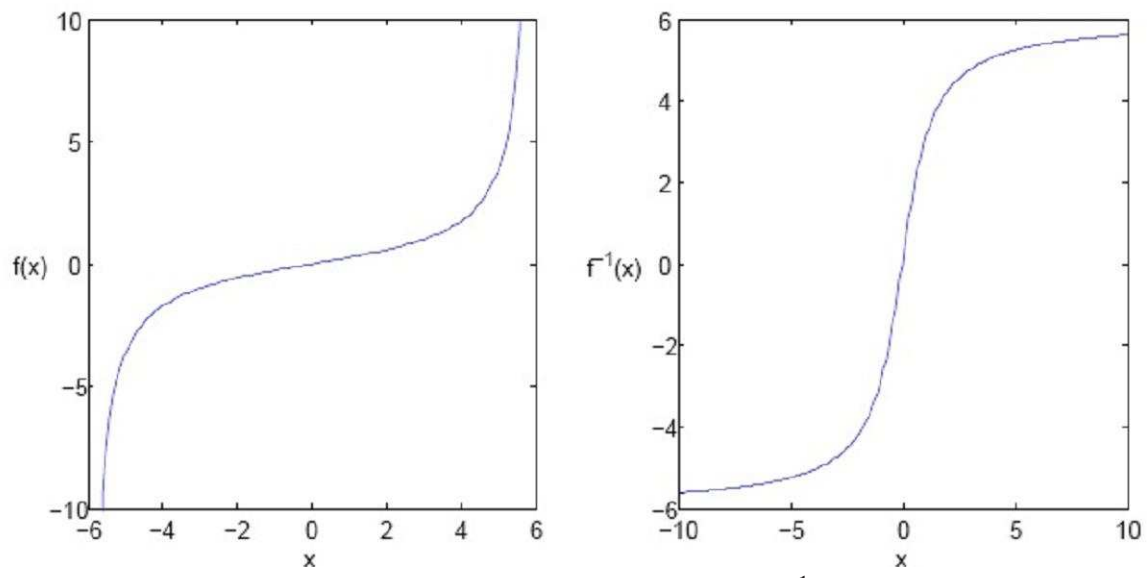

Figure 3. The graphic of $f(x)$ and $f^{-1}(x)$

(2) $\lambda \bar{l}_{\alpha}=\bar{l}_{f-1[\lambda f(\alpha)]}$.

\section{Proof. \\ (1) \\ (1) $\quad \bar{l}_{\beta}$ $\bar{l}_{\beta}=$} $\left.+g\left(\bar{l}_{\beta}\right)\right]=g^{-1}[f(\alpha)+f(\beta)]=\bar{l}_{f^{-1}[f(\alpha)+f(\beta)]} ;$

(2) $\lambda \bar{l}_{\alpha}=g^{-1}\left[\lambda g\left(\bar{l}_{\alpha}\right)\right]=g^{-1}[\lambda f(\alpha)]=\bar{l}_{f^{-1}[\lambda f(\alpha)]}$.

Definition 3 defines the addition operation and scalar multiplication operation based on the mapping $g\left(\bar{l}_{\alpha}\right): \bar{L} \rightarrow$ $R$ and $g^{-1}(x): R \rightarrow \bar{L}$. However, Property 1 simplifies the two operations based on the mapping $f(x): R \rightarrow R$ and $f^{-1}(x): R \rightarrow R$.

Example 2 Let $t=2$, for $\bar{l}_{0.5}, \bar{l}_{1.5}, \bar{l}_{1.7} \in \bar{L}$ and $9 \in R$, then

(1) $\bar{l}_{0.5} \oplus \bar{l}_{1.5}=\bar{l}_{f^{-1}[f(0.5)+f(1.5)]}=\bar{l}_{f^{-1}(1.2679)}=\bar{l}_{1.7246}$;

(2) $9 \bar{l}_{1.7}=\bar{l}_{f^{-1}[9 f(1.7)]}=\bar{l}_{f^{-1}(11.1141)}=\bar{l}_{2.8286}$.

Property 2 The linguistic term set $\bar{L}$ is a linear space in real number field $R$.

Proof. To prove that the linguistic term set $\bar{L}$ is a linear space, the following eight relations(1-8) above should be proved.
(1) For any two linguistic terms $\bar{l}_{\alpha}, \bar{l}_{\beta} \in \bar{L}, \bar{l}_{\alpha} \oplus \bar{l}_{\beta}=$ $\bar{l}_{\beta} \oplus \bar{l}_{\alpha}$.

For $\bar{l}_{\alpha}, \bar{l}_{\beta} \in \bar{L}$, then the left hand

$$
\bar{l}_{\alpha} \oplus \bar{l}_{\beta}=\bar{l}_{f^{-1}[f(\alpha)+f(\beta)]}
$$

and the right hand

$$
\bar{l}_{\beta} \oplus \bar{l}_{\alpha}=\bar{l}_{f^{-1}[f(\beta)+f(\alpha)]}=\bar{l}_{f^{-1}[f(\alpha)+f(\beta)]} .
$$

So, $\bar{l}_{\alpha} \oplus \bar{l}_{\beta}=\bar{l}_{\beta} \oplus \bar{l}_{\alpha}$.

(2) For any three linguistic terms $\bar{l}_{\alpha}, \bar{l}_{\beta}, \bar{l}_{\gamma} \in \bar{L},\left(\bar{l}_{\alpha} \oplus\right.$ $\left.\bar{l}_{\beta}\right) \oplus \bar{l}_{\gamma}=\bar{l}_{\alpha} \oplus\left(\bar{l}_{\beta} \oplus \bar{l}_{\gamma}\right)$.

For $\bar{l}_{\alpha}, \bar{l}_{\beta}, \bar{l}_{\gamma} \in \bar{L}$,

$\bar{l}_{\alpha} \oplus \bar{l}_{\beta}=\bar{l}_{f^{-1}[f(\alpha)+f(\beta)]}$,

$\bar{l}_{\beta} \oplus \bar{l}_{\gamma}=\bar{l}_{f^{-1}[f(\beta)+f(\gamma)]}$,

$l\left(\bar{l}_{\alpha} \oplus \bar{l}_{\beta}\right) \oplus \bar{l}_{\gamma}=\bar{l}_{f^{-1}\left\{f\left[f^{-1}(f(\alpha)+f(\beta))\right]+f(\gamma)\right\}}$ $=\bar{l}_{f^{-1}[f(\alpha)+f(\beta)+f(\gamma)]}$, 


$$
\begin{array}{r}
l l l \bar{l}_{\alpha} \oplus\left(\bar{l}_{\beta} \oplus \bar{l}_{\gamma}\right)=\bar{l}_{f(\alpha)+f^{-1}\left\{f\left[f^{-1}(f(\beta)+f(\gamma))\right]\right\}} \\
=\bar{l}_{f^{-1}[f(\alpha)+f(\beta)+f(\gamma)]} .
\end{array}
$$

So, $\left(\bar{l}_{\alpha} \oplus \bar{l}_{\beta}\right) \oplus \bar{l}_{\gamma}=\bar{l}_{\alpha} \oplus\left(\bar{l}_{\beta} \oplus \bar{l}_{\gamma}\right)$.

(3) For any element $\bar{l}_{\alpha} \in \bar{L}$, there exists an element $\bar{l}_{0} \in$ $\bar{L}$, such that $\bar{l}_{\alpha} \oplus \bar{l}_{0}=\bar{l}_{\alpha}$.

For any element $\bar{l}_{\alpha} \in \bar{L}$, there exists an element $\bar{l}_{0} \in \bar{L}$, such that $\bar{l}_{\alpha} \oplus \bar{l}_{0}=\bar{l}_{f^{-1}[f(\alpha)+f(0)]}=\bar{l}_{f^{-1}[f(\alpha)]}=\bar{l}_{\alpha}$.

(4) For any element $\bar{l}_{\alpha} \in \bar{L}$, there exists an element $\bar{l}_{-\alpha} \in \bar{L}$, such that $\bar{l}_{\alpha} \oplus \bar{l}_{-\alpha}=\bar{l}_{0}$.

For any element $\bar{l}_{\alpha} \in \bar{L}$, there exists an element $\bar{l}_{-\alpha} \in$ $\bar{L}$, such that $\bar{l}_{\alpha} \oplus \bar{l}_{-\alpha}=\bar{l}_{f^{-1}[f(\alpha)+f(-\alpha)]}=\bar{l}_{f^{-1}[f(\alpha)-f(\alpha)]}=$ $\bar{l}_{f^{-1}(0)}=\bar{l}_{0}$.

(5) $1 \cdot \bar{l}_{\alpha}=\bar{l}_{\alpha}$.

$1 \cdot \bar{l}_{\alpha}=\bar{l}_{f^{-1}[1 \cdot f(\alpha)]}=\bar{l}_{f^{-1}[f(\alpha)]}=\bar{l}_{\alpha}$.

(6) $\lambda_{1}\left(\lambda_{2} \bar{l}_{\alpha}\right)=\left(\lambda_{1} \lambda_{2}\right) \bar{l}_{\alpha}$.

$\bar{l}_{f-1}\left[\lambda_{1} \lambda_{2} f(\alpha)\right]$.

$\left(\lambda_{1} \lambda_{2}\right) \bar{l}_{\alpha}=\bar{l}_{f^{-1}\left[\lambda_{1} \lambda_{2} f(\alpha)\right]}$.

So, $\lambda_{1}\left(\lambda_{2} \bar{l}_{\alpha}\right)=\left(\lambda_{1} \lambda_{2}\right) \bar{l}_{\alpha}$.

(7) $\left(\lambda_{1}+\lambda_{2}\right) \bar{l}_{\alpha}=\lambda_{1} \bar{l}_{\alpha} \oplus \lambda_{2} \bar{l}_{\alpha}$.

$\left(\lambda_{1}+\lambda_{2}\right) \bar{l}_{\alpha}=\bar{l}_{f^{-1}\left[\left(\lambda_{1}+\lambda_{2}\right) f(\alpha)\right]}=\bar{l}_{f^{-1}\left[\lambda_{1} f(\alpha)+\lambda_{2} f(\alpha)\right]}$.

$\lambda_{1} \bar{l}_{\alpha} \oplus \lambda_{2} \bar{l}_{\alpha}=\bar{l}_{f^{-1}\left[\lambda_{1} f(\alpha)\right]} \oplus \bar{l}_{f^{-1}\left[\lambda_{2} f(\alpha)\right]}$

$=\bar{l}_{f^{-1}}\left\{f\left[f^{-1}\left(\lambda_{1} f(\alpha)\right)\right]+f\left[f^{-1}\left(\lambda_{2} f(\alpha)\right)\right]\right\}$

$=\bar{l}_{f^{-1}}\left[\lambda_{1} f(\alpha)+\lambda_{2} f(\alpha)\right]$.

So, $\left(\lambda_{1}+\lambda_{2}\right) \bar{l}_{\alpha}=\lambda_{1} \bar{l}_{\alpha} \oplus \lambda_{2} \bar{l}_{\alpha}$.

(8) $\lambda\left(\bar{l}_{\alpha} \oplus \bar{l}_{\beta}\right)=\lambda \bar{l}_{\alpha} \oplus \lambda \bar{l}_{\beta}$.

$\lambda\left(\bar{l}_{\alpha} \oplus \bar{l}_{\beta}\right)=\lambda \bar{l}_{f^{-1}[f(\alpha)+f(\beta)]}$

$=\bar{l}_{f-1}\left\{\lambda f\left[f^{-1}(f(\alpha)+f(\beta))\right]\right\}$

$=\bar{l}_{f^{-1}[\lambda f(\alpha)+\lambda f(\beta)]}$.

$\lambda \bar{l}_{\alpha} \oplus \lambda \bar{l}_{\beta}=\bar{l}_{f^{-1}[\lambda f(\alpha)]} \oplus \bar{l}_{f^{-1}[\lambda f(\beta)]}$

$=\bar{l}_{f^{-1}}\left\{f\left[f^{-1}(\lambda f(\alpha))\right]+f\left[f^{-1}(\lambda f(\beta))\right]\right\}$

$=\bar{l}_{f^{-1}}[\lambda f(\alpha)+\lambda f(\beta)]$.

So, $\lambda\left(\bar{l}_{\alpha} \oplus \bar{l}_{\beta}\right)=\lambda \bar{l}_{\alpha} \oplus \lambda \bar{l}_{\beta}$.

Based on the defined operators in $\bar{L}$, the linguistic information entropy and linguistic weighted arithmetic average operator will be introduced.

\subsection{Linguistic weighted arithmetic average( $L W A A)$ operator}

In the evaluation problem of a scenic spot, let $U=\left\{u_{1}, u_{2}, \cdots, u_{n}\right\}$ be the set of evaluation indicator set and $S=\left\{s_{1}, s_{2}, \cdots, s_{m}\right\}$ be the set of the surveyed tourists. Each surveyed tourist evaluates each evaluation indicator and the evaluation linguistic matrix $\bar{l}_{A}=\left(\bar{l}_{a_{i j}}\right)_{m \times n}$ is shown in Table 5,

where $\bar{l}_{a_{i j}}(i=1,2, \cdots, m ; j=1,2, \cdots, n)$ indicates that the $i$ th surveyed tourist's satisfaction degree toward the $j$ th evaluation indicator.
Table 5: The evaluation linguistic matrix

\begin{tabular}{ccccc}
\hline & $u_{1}$ & $u_{2}$ & $\cdots$ & $u_{n}$ \\
\hline$s_{1}$ & $\bar{l}_{a_{11}}$ & $\bar{l}_{a_{12}}$ & $\cdots$ & $\bar{l}_{a_{1 n}}$ \\
$s_{2}$ & $\bar{l}_{a_{21}}$ & $\bar{l}_{a_{22}}$ & $\cdots$ & $\bar{l}_{a_{2 n}}$ \\
$\vdots$ & $\vdots$ & $\vdots$ & $\ddots$ & $\vdots$ \\
$s_{m}$ & $\bar{l}_{a_{m 1}}$ & $\bar{l}_{a_{m 2}}$ & $\cdots$ & $\bar{l}_{a_{m n}}$ \\
\hline
\end{tabular}

To get a comprehensive evaluation of a scenic spot, all tourists' evaluation information and all the evaluation indicators should be taken into account. To aggregate each tourist's evaluation information and the group evaluation value of each indicators, a weight generation method in linguistic environment is introduced to get the weight of each evaluation indicator, and a linguistic weighted arithmetic average operator is introduced to aggregate linguistic information.

3.2.1 A weight generation method in linguistic environment

To generate the weight of each evaluation indicator in linguistic environment, $\mathrm{Wu}$ and Chen [24] proposed a maximizing deviation method. A idea point method is proposed by $\mathrm{Xu}$ [25] to establish optimize model to generate attribute weights in dealing with multiple attribute decision making with incomplete weight information. Liu [26] used a professor assessing method to generate the weight of each indictor. Xu and Da [27] proposed a standard deviation method and a mean deviation method to generate the weight of evaluation indicator. However, almost all these existed methods in linguistic environment should solve models. To simplify the process of generating the weight, a linguistic variance method is proposed.

Definition 4 Let $\bar{l}_{\alpha}=\left(\bar{l}_{\alpha_{1}}, \bar{l}_{\alpha_{2}}, \cdots, \bar{l}_{\alpha_{m}}\right)^{T}$ be a linguistic vector, then the expectation and variance of $\bar{l}_{\alpha}$ can be calculated by the formula:

(1) $E\left(\bar{l}_{\alpha}\right)=\frac{1}{m}\left(\bar{l}_{\alpha_{1}} \oplus \bar{l}_{\alpha_{2}} \oplus \cdots \oplus \bar{l}_{\alpha_{m}}\right)$;

(2) $D\left(\bar{l}_{\alpha}\right)=\frac{1}{m} \sum_{i=1}^{m}\left\{g\left(\bar{l}_{\alpha_{i}}\right)-g\left[E\left(\bar{l}_{\alpha}\right)\right]\right\}^{2}$.

Property 3

(1) $E\left(\bar{l}_{\alpha}\right)=\bar{l}_{\bar{\alpha}}$, where $\bar{\alpha}=f^{-1}\left[\frac{1}{m} \sum_{i=1}^{m} f\left(\alpha_{i}\right)\right]$;

(2) $D\left(\bar{l}_{\alpha}\right)=\frac{1}{m} \sum_{i=1}^{m}\left[f\left(\alpha_{i}\right)-\frac{1}{m} \sum_{i=1}^{m} f\left(\alpha_{i}\right)\right]^{2}$.

Proof.

$$
\begin{aligned}
& \text { (1)E( } \left.\bar{l}_{\alpha}\right)=\frac{1}{m}\left(\bar{l}_{\alpha_{1}} \oplus \bar{l}_{\alpha_{2}} \oplus \cdots \oplus \bar{l}_{\alpha_{m}}\right) \\
& =\frac{1}{m} \bar{l}_{f^{-1}\left[\sum_{i=1}^{m} f\left(\alpha_{i}\right)\right]} \\
& =\bar{l}_{f^{-1}\left[\frac{1}{m} \sum_{i=1}^{m} f\left(\alpha_{i}\right)\right]} \text {; } \\
& \text { (2) } D\left(\bar{l}_{\alpha}\right)=\frac{1}{m} \sum_{i=1}^{m}\left[g\left(\bar{l}_{\alpha_{i}}\right)-g\left(\bar{l}_{\bar{\alpha}}\right)\right]^{2} \\
& =\frac{1}{m} \sum_{i=1}^{m}\left[f\left(\alpha_{i}\right)-f(\bar{\alpha})\right]^{2} \\
& =\frac{1}{m} \sum_{i=1}^{m}\left[f\left(\alpha_{i}\right)-\frac{1}{m} \sum_{i=1}^{m} f\left(\alpha_{i}\right)\right]^{2} .
\end{aligned}
$$

Example 3 Let $\bar{l}_{\alpha}=\left(\bar{l}_{-0.5,}, \bar{l}_{0.4}, \bar{l}_{0.9}, \bar{l}_{1.5}\right)^{T}$. Then $E\left(\bar{l}_{\alpha}\right) \quad=\quad \bar{l}_{\bar{\alpha}}, \quad$ where $\bar{\alpha}=f^{-1}\left\{\frac{1}{4}[f(-0.5)+f(0.4)+f(0.9)+f(1.5)]\right\}=$ 
$f^{-1}\left[\frac{1}{4}(-0.2679+0.2126+0.5095+1)\right]=$

$f^{-1}(0.3635)=0.6659$. So, $E\left(\bar{l}_{\alpha}\right)=\bar{l}_{0.6659}$.

$$
D\left(\bar{l}_{\alpha}\right)=\frac{1}{4} \sum_{i=1}^{4}\left[f\left(\alpha_{i}\right)-\frac{1}{4} \sum_{i=1}^{4} f\left(\alpha_{i}\right)\right]^{2}
$$

$=\frac{1}{4} \sum_{i=1}^{4}\left[f\left(\alpha_{i}\right)-f(\bar{\alpha})\right]^{2}$

$=\frac{1}{4}\left\{[f(-0.5)-f(0.6659)]^{2}+[f(0.4)-f(0.6659)]^{2}+\right.$

$\left.[f(0.9)-f(0.6659)]^{2}+[f(1.5)-f(0.6659)]^{2}\right\}=0.2120$.

\section{Property 4}

Let $\bar{l}_{\alpha}=\left(\bar{l}_{\alpha_{1}}, \cdots, \bar{l}_{\alpha_{v}}, *, \cdots, *, \bar{l}_{\alpha_{v+t+1}}, \cdots, \bar{l}_{\alpha_{m}}\right)^{T}$ be an incomplete linguistic vector,and $\bar{l}_{\alpha^{\prime}}=\left(\bar{l}_{\alpha_{1}}, \cdots, \bar{l}_{\alpha_{v}}, \bar{l}_{\beta}, \cdots, \bar{l}_{\beta}\right.$,

$\left.\bar{l}_{\alpha_{v+t+1}}, \cdots, \bar{l}_{\alpha_{m}}\right)^{T}$ be the completed linguistic vector. Then

$$
E\left(\bar{l}_{\alpha}\right)=E\left(\bar{l}_{\alpha^{\prime}}\right)
$$

where $E\left(\bar{l}_{\alpha}\right)=\bar{l}_{\beta}$, $\beta=f^{-1}\left\{\frac{1}{m-t}\left[\sum_{i=1}^{v} f\left(\alpha_{i}\right)+\sum_{i=v+t}^{m} f\left(\alpha_{i}\right)\right]\right\}$.

Proof. Note $E\left(\bar{l}_{\alpha^{\prime}}\right)=\bar{l}_{\gamma}$. Then

$$
\gamma=f^{-1}\left\{\frac{1}{m}\left[\sum_{i=1}^{v} f\left(\alpha_{i}\right)+t f(\beta)+\sum_{i=v+t}^{m} f\left(\alpha_{i}\right)\right]\right\} .
$$

For

$$
\beta=f^{-1}\left\{\frac{1}{m-t}\left[\sum_{i=1}^{v} f\left(\alpha_{i}\right)+\sum_{i=v+t}^{m} f\left(\alpha_{i}\right)\right]\right\}
$$

then

$$
\sum_{i=1}^{v} f\left(\alpha_{i}\right)+\sum_{i=v+t}^{m} f\left(\alpha_{i}\right)=(m-t) f(\beta)
$$

Thus,

$$
\begin{aligned}
\gamma & =f^{-1}\left\{\frac{1}{m}[t f(\beta)+(m-t) f(\beta)]\right\} \\
& =f^{-1}\left[\frac{m}{m} m f(\beta)\right] \\
& =f^{-1}[f(\beta)] \\
& =\beta .
\end{aligned}
$$

So, $E\left(\bar{l}_{\alpha}\right)=E\left(\bar{l}_{\alpha^{\prime}}\right)$.

Example 4 Let $\bar{l}_{\alpha}=\left(\bar{l}_{-0.5}, *, \bar{l}_{0.9}, \bar{l}_{1.5}\right)^{T}$. Then $E\left(\bar{l}_{\alpha}\right)=$ $\bar{l}_{\bar{\alpha}}$, where $\bar{\alpha}=f^{-1}\left\{\frac{1}{3}[f(-0.5)+f(0.9)+f(1.5)]\right\}=$ $f^{-1}\left[\frac{1}{3}(-0.2679+0.5095+1)\right]=f^{-1}(0.4139)=0.7495$. We can replace the incomplete linguistic vector $\bar{l}_{\alpha}$ by $\bar{l}_{\alpha^{\prime}}=$ $\left(\bar{l}_{-0.5}, \bar{l}_{0.7495}, \bar{l}_{0.9}, \bar{l}_{1.5}\right)^{T}$.

Note that $\bar{l}_{a . j}=\left(\bar{l}_{a_{1 j}}, \bar{l}_{a_{2 j}}, \cdots, \bar{l}_{a_{m j}}\right)^{T}(j=1,2, \cdots, n)$. With the definition of variance, which mirrors the bifurcation degree of evaluation information in satisfaction evaluation of a scenic spot, the weight $w_{j}$ of the $j$ th evaluation indicator can be gotten by

$$
w_{j}=\frac{D\left(\bar{l}_{a \cdot j}\right)}{\sum_{j=1}^{n} D\left(\bar{l}_{a \cdot j}\right)}, j=1,2, \cdots, n .
$$

In Section 2, a level empowerment system is generated by considering the gender, age, education background and occupation of the surveyed tourists. For the $k$ th surveyed person, if the weight of gender $v_{1}$, the weight of age $v_{2}$, the weight of education background $v_{3}$ and the weight of occupation $v_{4}$ are determined, then the weight of the $k$ th surveyed tourist can be calculated by
Table 6: The linguistic matrix evaluated by male

\begin{tabular}{ccccc}
\hline & $u_{1}$ & $u_{2}$ & $\cdots$ & $u_{n}$ \\
\hline$s_{11}$ & $\bar{l}_{b_{11}}$ & $\bar{l}_{b_{12}}$ & $\cdots$ & $\bar{l}_{b_{1 n}}$ \\
$s_{12}$ & $\bar{l}_{b_{21}}$ & $\bar{l}_{b_{22}}$ & $\cdots$ & $\bar{l}_{b_{2 n}}$ \\
$\vdots$ & $\vdots$ & $\vdots$ & $\ddots$ & $\vdots$ \\
$s_{1 m_{1}}$ & $\bar{l}_{b_{m_{1} 1}}$ & $\bar{l}_{b_{m_{1}}}$ & $\cdots$ & $\bar{l}_{b_{m_{1} n}}$ \\
\hline
\end{tabular}

Table 7: The linguistic matrix evaluated by female

\begin{tabular}{ccccc}
\hline & $u_{1}$ & $u_{2}$ & $\cdots$ & $u_{n}$ \\
\hline$s_{21}$ & $\bar{l}_{c_{11}}$ & $\bar{l}_{c_{12}}$ & $\cdots$ & $\bar{l}_{c_{1 n}}$ \\
$s_{22}$ & $\bar{l}_{c_{21}}$ & $\bar{l}_{c_{22}}$ & $\cdots$ & $\bar{l}_{c_{2 n}}$ \\
$\vdots$ & $\vdots$ & $\vdots$ & $\ddots$ & $\vdots$ \\
$s_{2 m_{2}}$ & $\bar{l}_{c_{m_{2} 1}}$ & $\bar{l}_{c_{m_{2} 2}}$ & $\cdots$ & $\bar{l}_{c_{m_{2} n}}$ \\
\hline
\end{tabular}

$w^{k}=v_{1} \cdot v_{2} \cdot v_{3} \cdot v_{4}$, where the value of $v_{i}$ is shown in Table 4. To determine the different weight of different gender, age, education background and occupation, the variance method is illustrated.

If there are $m_{1}$ male and $m_{2}$ female in the surveyed tourist, then the linguistic matrix evaluated by male is in Table 6 and the linguistic matrix evaluated by female is in Table 7.

In Table 6 , the variance of the $j$ th column linguistic evaluation information can be calculated by

$$
D\left(\bar{l}_{b_{\cdot j}}\right)=\frac{1}{m_{1}} \sum_{i=1}^{m_{1}}\left[f\left(b_{i j}\right)-\frac{1}{m_{1}} \sum_{i=1}^{m_{1}} f\left(b_{i j}\right)\right]^{2}, j=1,2, \cdots, n .
$$

Summing all the variance of each column, then the variance of linguistic evaluation information provided by male is

$$
D(\text { male })=\frac{1}{m_{1}} \sum_{j=1}^{n} \sum_{i=1}^{m_{1}}\left[f\left(b_{i j}\right)-\frac{1}{m_{1}} \sum_{i=1}^{m_{1}} f\left(b_{i j}\right)\right]^{2}
$$

In the same way, the variance of linguistic evaluation information provided by female in Table 7 can be calculated by

$$
D(\text { female })=\frac{1}{m_{2}} \sum_{j=1}^{n} \sum_{i=1}^{m_{2}}\left[f\left(c_{i j}\right)-\frac{1}{m_{2}} \sum_{i=1}^{m_{2}} f\left(c_{i j}\right)\right]^{2} .
$$

Then the weight of male $v_{11}$ and female $v_{12}$ in Table 4 can be gotten by

$$
\begin{aligned}
& v_{11}=\frac{D(\text { male })}{D(\text { male })+D(\text { female })} ; \\
& v_{12}=\frac{D(\text { female })}{D(\text { male })+D(\text { female })} .
\end{aligned}
$$

In the same way, all weights $v_{i j}(i=1,2,3,4 ; j=1,2, \cdots, 6)$ in Table 4 can be gotten. 


\subsubsection{The LWAA operator}

The evaluation indicator weight vector $W=\left(w_{1}, w_{2}\right.$, $\left.\cdots, w_{n}\right)^{T}$ can be gotten by Eq.(1). Then, a linguistic weighted arithmetic average operator is defined to aggregate the linguistic value of each evaluation indicator.

Definition 4 Let $\left\{\bar{l}_{\beta_{1}}, \bar{l}_{\beta_{2}}, \cdots, \bar{l}_{\beta_{n}}\right\}$ be a collection linguistic indicator value, a linguistic weighted arithmetic averaging ( $L W A A)$ operator is defined as

$$
\operatorname{LWAA}\left(\bar{l}_{\beta_{1}}, \bar{l}_{\beta_{2}}, \cdots, \bar{l}_{\beta_{n}}\right)=w_{1} \bar{l}_{\beta_{1}} \oplus w_{2} \bar{l}_{\beta_{2}} \oplus \cdots \oplus w_{n} \bar{l}_{\beta_{n}}=\bar{l}_{\beta},
$$

where $\beta=f^{-1}\left[\sum_{j=1}^{n} w_{j} f\left(\beta_{j}\right)\right], W=\left(w_{1}, w_{2}, \cdots, w_{n}\right)^{T}$ is the indicator weight vector, and $w_{j} \geq 0(j=1,2, \cdots, n)$, $\sum_{j=1}^{n} w_{j}=1$.

Example 5 Suppose $\left\{\bar{l}_{-0.5}, \bar{l}_{0.4}, \bar{l}_{0.9}, \bar{l}_{1.5}\right\}$ be the collection linguistic indicator value and $W=(0.1,0.2,0.3,0.4)^{T}$ be the indicator weight vector, then

$\operatorname{LWAA}\left(\bar{l}_{-0.5}, \bar{l}_{0.4}, \bar{l}_{0.9}, \bar{l}_{1.5}\right)$

$0.1 \cdot \bar{l}_{-0.5} \oplus 0.2 \cdot \bar{l}_{0.4} \oplus 0.3 \cdot \bar{l}_{0.9} \oplus 0.4 \cdot \bar{l}_{1.5}=\bar{l}_{\beta}$,

where $\beta=f^{-1}[0.1 f(-0.5)+0.2 f(0.4)+0.3 f(0.9)+$

$0.4 f(1.5)]=f^{-1}[0.1 f(-0.5)+0.2 f(0.4)+0.3 f(0.9)+$ $0.4 f(1.5)]=f^{-1}(0.5686)=0.9874$.

So, $\quad \operatorname{LWAA}\left(\bar{l}_{-0.5}, \bar{l}_{0.4}, \bar{l}_{0.9}, \bar{l}_{1.5}\right)=$ $0.1 \cdot \bar{l}_{-0.5} \oplus 0.2 \cdot \bar{l}_{0.4} \oplus 0.3 \cdot \bar{l}_{0.9} \oplus 0.4 \cdot \bar{l}_{1.5}=\bar{l}_{0.9874}$.

For the new defined $L W A A$ operator, the following four properties proposed by $\mathrm{Wu}$ and Chen [24] are all satisfied.

Property 5 If $\bar{l}_{\beta_{j}} \leq \bar{l}_{\gamma_{j}}(\forall j \in I)$, then

$\operatorname{LWAA}\left(\bar{l}_{\beta_{1}}, \bar{l}_{\beta_{2}}, \cdots, \bar{l}_{\beta_{n}}\right) \leq \operatorname{LWAA}\left(\bar{l}_{\gamma_{1}}, \bar{l}_{\gamma_{2}}, \cdots, \bar{l}_{\gamma_{n}}\right)$, where $I=\{1,2, \cdots, n\}$.

Proof.

$\operatorname{LWAA}\left(\bar{l}_{\beta_{1}}, \bar{l}_{\beta_{2}}, \cdots, \bar{l}_{\beta_{n}}\right)=\bar{l}_{f^{-1}\left[\sum_{j=1}^{n} w_{j} f\left(\beta_{j}\right)\right]}$,

$\operatorname{LWAA}\left(\bar{l}_{\gamma_{1}}, \bar{l}_{\gamma_{2}}, \cdots, \bar{l}_{\gamma_{n}}\right)=\bar{l}_{f^{-1}\left[\sum_{j=1}^{n} w_{j} f\left(\gamma_{j}\right)\right]}$.

For $\bar{l}_{\beta_{j}} \leq \bar{l}_{\gamma_{j}}(\forall j \in I)$, then $\beta_{j} \leq \gamma_{j}(\forall j \in I)$.

For both $f(x)$ and $f^{-1}(x)$ are increasing function, thus, $f^{-1}\left[\sum_{j=1}^{n} w_{j} f\left(\beta_{j}\right)\right] \leq f^{-1}\left[\sum_{j=1}^{n} w_{j} f\left(\gamma_{j}\right)\right]$. So, $\operatorname{LWAA}\left(\bar{l}_{\beta_{1}}, \bar{l}_{\beta_{2}}, \cdots, \bar{l}_{\beta_{n}}\right) \leq \operatorname{LWAA}\left(\bar{l}_{\gamma_{1}}, \bar{l}_{\gamma_{2}}, \cdots, \bar{l}_{\gamma_{n}}\right)$.

\section{Property 6}

$\min _{j \in I} \bar{l}_{\beta_{j}} \leq \operatorname{LWAA}\left(\bar{l}_{\beta_{1}}, \bar{l}_{\beta_{2}}, \cdots, \bar{l}_{\beta_{n}}\right) \leq \max _{j \in I} \bar{l}_{\beta_{j}}$, where $I=\{1,2, \cdots, n\}$.

Proof. Let $\min _{j \in I} \bar{l}_{\beta_{j}}=\bar{l}_{\beta_{m}}$ and $\max _{j \in I} \bar{l}_{\beta_{j}}=\bar{l}_{\beta_{M}}$. Then $\operatorname{LWAA}\left(\bar{l}_{\beta_{1}}, \bar{l}_{\beta_{2}}, \cdots, \bar{l}_{\beta_{n}}\right) \leq w_{1} \bar{l}_{\beta_{M}} \oplus w_{2} \bar{l}_{\beta_{M}} \oplus \cdots \oplus w_{n} \bar{l}_{\beta_{M}}$ $=\left(w_{1}+w_{2}+\cdots+w_{n}\right) \bar{l}_{\beta_{M}}=\bar{l}_{\beta_{M}}=\max _{j \in I} \bar{l}_{\beta_{j}} ;$

$\operatorname{LWAA}\left(\bar{l}_{\beta_{1}}, \bar{l}_{\beta_{2}}, \cdots, \bar{l}_{\beta_{n}}\right) \geq w_{1} \bar{l}_{\beta_{m}} \oplus w_{2} \bar{l}_{\beta_{m}} \oplus \cdots \oplus w_{n} \bar{l}_{\beta_{m}}$ $=\left(w_{1}+w_{2}+\cdots+w_{n}\right) \bar{l}_{\beta_{m}}=\bar{l}_{\beta_{m}}=\min _{j \in I} \bar{l}_{\beta_{j}}$.

Property 7 If $\bar{l}_{\beta_{j}}=\bar{l}_{\beta}(\forall j \in I)$, then

$\operatorname{LWAA}\left(\bar{l}_{\beta_{1}}, \bar{l}_{\beta_{2}}, \cdots, \bar{l}_{\beta_{n}}\right)=\bar{l}_{\beta}$, where $I=\{1,2, \cdots, n\}$. Proof.

$\operatorname{LWAA}\left(\bar{l}_{\beta_{1}}, \bar{l}_{\beta_{2}}, \cdots, \bar{l}_{\beta_{n}}\right)=w_{1} \bar{l}_{\beta_{1}} \oplus w_{2} \bar{l}_{\beta_{2}} \oplus \cdots \oplus w_{n} \bar{l}_{\beta_{n}}=$ $w_{1} \bar{l}_{\beta} \oplus w_{2} \bar{l}_{\beta} \oplus \cdots \oplus w_{n} \bar{l}_{\beta}=\left(w_{1}+w_{2}+\cdots+w_{n}\right) \bar{l}_{\beta}=\bar{l}_{\beta}$.

Property 8 If $W=(1 / n, 1 / n, \cdots, 1 / n)^{T}$, then the $L W A A$ operator is reduced to linguistic arithmetic average
$(L A A)$ operator, such as $\operatorname{LWAA}\left(\bar{l}_{\beta_{1}}, \bar{l}_{\beta_{2}}, \cdots, \bar{l}_{\beta_{n}}\right)=\bar{l}_{\beta}$, where $\beta=f^{-1}\left[\frac{1}{n} \sum_{j=1}^{n} f\left(\beta_{j}\right)\right]$.

$$
\text { Proof. } L W A A\left(\bar{l}_{\beta_{1}}, \bar{l}_{\beta_{2}}, \cdots, \bar{l}_{\beta_{n}}\right)=\bar{l}_{f^{-1}\left[\sum_{j=1}^{n} w_{j} f\left(\beta_{j}\right)\right]}
$$$$
=\bar{l}_{f^{-1}\left[\sum_{j=1}^{n} \frac{1}{n} f\left(\beta_{j}\right)\right]}=\bar{l}_{f^{-1}\left[\frac{1}{n} \sum_{j=1}^{n} f\left(\beta_{j}\right)\right]} \text {. }
$$

\subsubsection{The satisfaction evaluation process}

Based on the discussion above, a satisfaction evaluation process of a scenic spot will be introduced.

Step 1: Screen the satisfaction information of each surveyed tourist whose integrality is above $60 \%$ and complete the incomplete linguistic satisfaction information in every satisfaction evaluation indicator by Property 4.

Step 2: According to the background of each surveyed tourist, cluster the satisfaction information by gender, age, education background and occupation, calculate the level weights $v_{i j}(i=1,2,3,4 ; j=1,2, \cdots, 6)$ in Figure 1 by Eq.(6) and generate the weight $w^{k}$ of each surveyed person by Eq.(1).

Step 3: In every evaluation indicator $u_{j}$, aggregate the satisfaction information of each surveyed tourist by

$$
\bar{l}_{a_{j}}=w^{1} \bar{l}_{a_{1 j}} \oplus w^{2} \bar{l}_{a_{2 j}} \oplus \cdots \oplus w^{m} \bar{l}_{a_{m j}}, j=1,2, \cdots, n .
$$

and get the group satisfaction evaluation information $\bar{l}_{a_{j}}$ toward the evaluation indictor $u_{j}$.

Step 4: Calculate the weight $w_{j}$ of $j$ th evaluation indicator by Eq.(2) and aggregate the group satisfaction evaluation information $\bar{l}_{a_{j}}$ in every evaluation indicator $u_{j}$ by Eq.(7).

With the four steps above, the overall merit of satisfaction of a scenic spot can be gotten. In section 4, an evaluation case of tourist satisfaction in Jiuzhai Valley is illustrated to explain the evaluation process.

\section{A satisfaction evaluation case}

Jiuzhai Valley is a national park located in the range of Min Shan mountain, Northern Sichuan in Southwestern China. It is best-known for its fabled blue and green lakes, spectacular waterfalls, narrow conic karst land forms and its unique wildlife. It was declared a UNESCO World Heritage Site in 1992; the park joined the Man and Biosphere Conservation Network in 1997 and has also received IUCN and ISO 14,001 accreditations. More than 20 million tourists from all over the world visit the Valley every year. A satisfaction survey has been done in Jiuzhai Valley, and 833 tourists filled in questionnaires. To evaluate the feelings of the Valley, the following steps can be conducted. 
Table 8: The calculation results of the level weights

\begin{tabular}{|c|c|c|c|}
\hline Characteristic & & Characteristic & \\
\hline$\overline{\operatorname{Gender}}\left(v_{1}\right)$ & & $\operatorname{Age}\left(v_{2}\right)$ & \\
\hline$v_{11}$ & 0.5155 & $v_{21}$ & 0.3133 \\
\hline \multirow[t]{4}{*}{$v_{12}$} & 0.4845 & $v_{22}$ & 0.2082 \\
\hline & & $v_{23}$ & 0.1947 \\
\hline & & $v_{24}$ & 0.1446 \\
\hline & & $v_{25}$ & 0.1412 \\
\hline Background of education $\left(v_{3}\right)$ & & $\operatorname{Occupation}\left(v_{4}\right)$ & \\
\hline$v_{31}$ & 0.2233 & $v_{41}$ & 0.1553 \\
\hline$v_{32}$ & 0.1830 & $v_{42}$ & 0.1576 \\
\hline$v_{33}$ & 0.2175 & $v_{43}$ & 0.2008 \\
\hline$v_{34}$ & 0.1789 & $v_{44}$ & 0.1036 \\
\hline$v_{35}$ & 0.1974 & $v_{45}$ & 0.1416 \\
\hline$v_{46}$ & 0.2410 & & \\
\hline
\end{tabular}

Table 9: Aggregation of the group satisfaction evaluation information

\begin{tabular}{llllll}
\hline EI & $\bar{l}_{a_{j}}$ & Weight & EI & $\bar{l}_{a_{j}}$ & Weight \\
\hline BT & $\bar{l}_{2.0052}$ & 0.0336 & DC & $\bar{l}_{0.1588}$ & 0.0452 \\
BW & $\bar{l}_{1.8710}$ & 0.0394 & DS & $\bar{l}_{0.6088}$ & 0.0396 \\
BP & $\bar{l}_{1.7157}$ & 0.0391 & DP & $\bar{l}_{-0.4781}$ & 0.0492 \\
BL & $\bar{l}_{1.8608}$ & 0.0367 & AC & $\bar{l}_{0.7265}$ & 0.0369 \\
BS & $\bar{l}_{1.8681}$ & 0.0345 & AH & $\bar{l}_{0.7188}$ & 0.0394 \\
MTS & $\bar{l}_{0.8716}$ & 0.0417 & AP & $\bar{l}_{0.5344}$ & 0.0338 \\
MTP & $\bar{l}_{1.1475}$ & 0.0399 & EC & $\bar{l}_{0.6986}$ & 0.0296 \\
MS & $\bar{l}_{2.2367}$ & 0.0310 & EA & $\bar{l}_{0.9157}$ & 0.0305 \\
MD & $\bar{l}_{-0.3740}$ & 0.0545 & ES & $\bar{l}_{1.0792}$ & 0.0289 \\
SET & $\bar{l}_{1.5353}$ & 0.0309 & EP & $\bar{l}_{0.6611}$ & 0.0325 \\
SEG & $\bar{l}_{1.5139}$ & 0.0339 & SHS & $\bar{l}_{0.8726}$ & 0.0318 \\
SEC & $\bar{l}_{1.5480}$ & 0.0286 & SHV & $\bar{l}_{0.8576}$ & 0.0304 \\
SEH & $\bar{l}_{1.1754}$ & 0.0169 & SHF & $\bar{l}_{0.9062}$ & 0.0304 \\
DF & $\bar{l}_{-0.1450}$ & 0.0455 & SHP & $\bar{l}_{0.4547}$ & 0.0357 \\
\hline Overall evaluation & $\bar{l}_{0.1008}$ & & & & \\
\hline
\end{tabular}

Step 1: Screen the satisfaction information of each surveyed tourist whose integrality is above $60 \%$, and 737 questionnaires are screened out. And complete the incomplete linguistic satisfaction information in every satisfaction evaluation indicator by Property 4 .

Step 2: To generate the weight of each surveyed tourist, according to their background, cluster the satisfaction information by gender, age, education background and occupation, and calculate the level weights $v_{i j}(i=1,2,3,4 ; j=1,2, \cdots, 6)$ in Figure 1 by Eq.(6). Then the calculation results of the level weights $v_{i j}(i=1,2,3,4 ; j=1,2, \cdots, 6)$ are shown in Table 8 . Then, according to the $k$ th tourist's background, the weight $w^{k}$ of the $k$ th tourist can be given by Eq.(1).

Step 3: In every evaluation indicator $u_{j}$, aggregate the satisfaction information of each surveyed tourist by

$$
\bar{l}_{a_{j}}=w^{1} \bar{l}_{a_{1 j}} \oplus w^{2} \bar{l}_{a_{2 j}} \oplus \cdots \oplus w^{m} \bar{l}_{a_{m j}}, j=1,2, \cdots, n,
$$

and get the group of satisfaction evaluation information $\bar{l}_{a_{j}}$ toward the evaluation indicator $u_{j}$, the result is shown in Table 9. All the evaluation indicators can be divided to two parts: The first part is the dissatisfaction indicators: Degree of crowdedness, Features of drinks and foods,
Price of drinks and foods, which is needed to be improved urgently. The other evaluation indicators are the second part, which the tourists are satisfied.

Step 4: Calculate the weight $w_{j}$ of $j$ th evaluation indicator by Eq.(2) and the weight information is shown in Table 9. Through the weight of each evaluation indicator, we can see that the following evaluation indicator is the most important in satisfaction evaluation: Ticket price of scenic spot, Degree of crowdedness, Features of drinks and foods, Convenience of drinks and foods and Price of drinks and foods. Aggregate the group satisfaction evaluation information $\bar{l}_{a_{j}}$ in every evaluation indicator $u_{j}$ by Eq.(7), and the result is shown in Table 9.

With the up steps, the overall merit of tourist satisfaction of Jiuzhai Valley is a little satisfied. And Jiuzhai Valley can improve its tourist satisfaction by the improvement of Degree of crowdedness, Features of drinks and foods and Price of drinks and foods. 


\section{Conclusion}

Based on the level empowerment system and the $L W A A$ operator, a satisfaction evaluation process is proposed in this paper. Firstly, by the established evaluation indicator system of two levels, an evaluation survey is made in Jiuzhai Valley and 833 tourists are surveyed. According to their different backgrounds, a level empowerment system is established to generate the weight of each surveyed tourist. Secondly, considering the evaluation information is the natural language in linguistic term set $L$, the linguistic term set is extended to a continuous linguistic term set $\bar{L}$ and addition operation and scalar multiplication are defined in $\bar{L}$ based on the mapping $g\left(\bar{l}_{\alpha}\right)$ and $g^{-1}(x)$. Thirdly, the expectation and variance in linguistic variable environment are defined and a indicator weight generation method is introduced by the linguistic information variance. Fourthly, a linguistic weighted arithmetic average $(L W A A)$ operator is introduced to aggregate the evaluation information of each surveyed tourist and the group evaluation information of each indicator. Finally, a satisfaction evaluation process is given and the case of Jiuzhai Valley is illustrated to explain the evaluation process.

\section{Acknowledgement}

This research was supported by the National Natural Science Foundation of China (Grant No. 71001075 and 71261001), the Major International Joint Research Program of the National Natural Science Foundation of China (Grant No.71020107027), Central University Fund of Sichuan Unversity No. skqy201112, the National High Technology Research and Development Major Program of China (863 Program) (Grant No. 2008AA04A107), and Special Research Fund Program of Higher Education of China for the Doctoral Subject (No. 20110181110034).

\section{References}

[1] X. Wang, J. Zhang, C. Gu, F. Zhen. Examining antecedents and consequences of tourist satisfaction: A structural modeling approach. Tsinghus Science and Technology, 14, 397-406 (2009).

[2] R. L. Oliver. A cognitive model of the antecedents and consequences of satisfaction decision. Journal of Marketing Research, 17, 460-469 (1980).

[3] C. Fornell. A national customer satisfaction barometer: The Swedish experiences. Journal of Marketing, 56, 6-21 (1992).

[4] E. W.Anderson, C. Fornell, D. R. Lehmann. Customer satisfaction, market share, and profitability: Findings from Sweden. Journal of Marketing, 58, 53-66 (1994).

[5] C.Fornell, M. D.Johnson, E. W.Anderson, et al. The American customer satisfaction index: Description, findings, and implications. Journal of Marketing, 60, 7-18 (1996).
[6] D.A.Baker, J. L. Crompton. Quality, satisfaction and behavioral intentions. Annals of Tourism Research, 27, 785-804 (2000)

[7] A. Pizam, N. Uriely, A.Reichel. The intensity of tourist host social relationship and its effects on satisfaction and change of attitudes: the case of working tourists in Israel. Tourism Management, 21, 395-406 (2000).

[8] K.Nield, M.Kozak, G.LeGrys. The role of food service in tourist satisfaction. Hospitality Management, 19, 375-384 (2000).

[9] M. Kozak. Comparative assessment of tourist satisfaction with destinations across two nationalities.Tourism Management, 22, 391-401 (2001).

[10] L. Yu, M. Goulden. A comparative analysis of international touristssatisfaction in Mongolia. Tourism Management, 27, 1331-1342 (2006).

[11] T. K. Hui, D. Wan, A. Ho. Tourists' satisfaction, recommendation and revisiting Singapore. Tourism Management, 12, 965-975 (2007).

[12] C. G. Q. Chi, H. Qu. Examining the structural relationships of destination image,tourist satisfaction and destination loyalty: An integrated approach. Tourism Management, 29, 624-636 (2008).

[13] J. Alegre, J. Garau. Tourst satisfaction and dissatisfaction. Annals of Tourism Research, 37, 52-73 (2010).

[14] S. Lee, S. Jeon, D. Kim. The impact of tour quality and tourist satisfaction on tourist loyalty: The case of Chinese tourists in Korea. Tourism Management, 32, 1115-1124 (2011).

[15] C. Torres-Sovero, J. A. Gonzlez, B. Martłn-Lpez, C.A.Kirkby. Social-ecological factors influencing tourist satisfaction in three ecotourism lodges in the southeastern Peruvian Amazon. Tourism Management, 33, 545-552 (2012).

[16] J. Mikulic, D. Prebezac. Using dummy regression to explore asymmetric effects in tourist satisfaction: A cautionary note. Tourism Management, 33, 713-716 (2012).

[17] H.Song, R. V. D. Veen, G. Li, J. L.Chen. The HongKong tourist satisfaction index. Annals of Tourism Research, 39, 459-479 (2012)

[18] E. Babakus, W. G. Mangold. Adapting the servqual scale to hospital services: An empirical investigation. Health Services Research, 26, 767-786 (1992).

[19] Z. S. Xu, A method based on linguistic aggregation operators for group decision making with linguistic preference relations. Information Sciences, 166, 19-30 (2004).

[20] F. Herrera, E. Herrera-Viedma. Choice functions and mechanisms for linguistic preference relations. European Journal of Operational Research, 120, 144-161 (2000).

[21] F. Herrera, E. Herrera-Viedma, J. L. Verdegay. Direct approach processed in group decision making using linguistic OWA operators. Fuzzy Sets and Systems, 79, 175190 (1996).

[22] H. Herrera, E. Herrera-Viedma, J. L. Verdegay. A sequential selection process in group decision making with a linguistic assessment approach. Information Sciences, 85, 223-239 (1995).

[23] Z.S.Xu. Induced uncertain linguistic OWA operators applied to group decision making. Information Fusion, 7, 231-238 (2006). 
[24] Z. B. Wu, Y. H.Chen. The maximizing deviation method for group multiple attribute decision making under linguistic environment. Fuzzy Sets and Systems, 158, 1608-1617 (2007).

[25] Z. S. Xu. A method for multiple attribute decision making within complete weight information in linguistic setting. Knowledge-BasedSystem, 20, 719-725 (2007).

[26] P. Liu, X. Zhang, W. Liu. A risk evaluation method for the high-tech project investment based on uncertain linguistic variables. Technological Forecasting\&Social Change, 78, 40-50 (2011).

[27] Y.Xu, Q.Da. Standard and mean deviation methods for linguistic group decision making and their applications. Expert Systems with Applications, 37, 5905-5912 (2010).

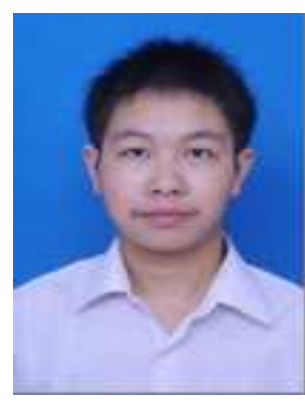

hmm0112@126.com.

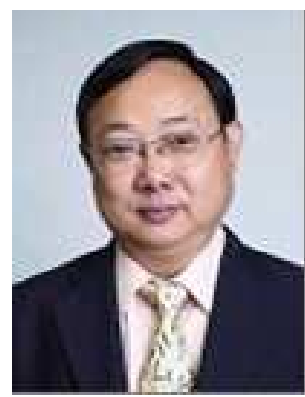

Mingming $\mathrm{Hu}$ is a Doctoral student in Sichuan University for majoring in management science and engineering, and a member of Information and Business Management Institute of Sichuan University. His research interests are the fuzzy decision and the fuzzy evaluation. Contact him at

\section{Peiyu}

Ren is a Professor, $\mathrm{PhD}$ Supervisor, currently acting as the Director of Information and Business Management Research Institute of Sichuan University. He has presided over and completed five surface projects of National Natural Science Foundation of China, being in charge of project research of Projects 863, 985 and 211, having published 15 books, monographs and more than 100 academic papers, including SCI, EI and CSSCI. Contact him at renpy.scu@163.com.

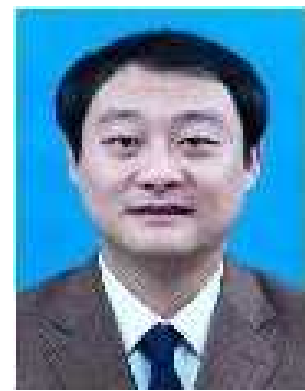

Maozhu Jin is an instructor of Business School, the tutor of MBA operations management and innovation and entrepreneurship management

in Sichuan University. He has been engaged in the teaching of core curriculums such as operations management and management consulting. His current research interests include the areas of operations management, organizational process reengineering, strategic management, service operations management, platform-based mass customization and risk management. As a main researcher, he has participated in and completed three projects supported by National Natural Science Foundation of China and two surface projects. He has published two books and over ten research papers in authoritative journals of high quality both at home and abroad, and ten of them are retrieved by SCI and EI.

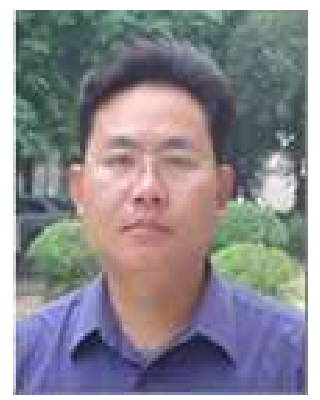

\section{Jibin}

Lan is a professor in Mathematics and Information Science Institute, Guangxi University. He obtained his $\mathrm{PhD}$ of Management Science and Engineering in the School of Economics Management, Southwest Jiaotong University. His major research interests are fuzzy multi-criteria decision, analytic hierarchy process and data mining. He has published in journals such as Knowledge-Based Systems, Mathematical and Computer Modeling, Foundations and Applications of Computational Intelligence, Artificial Intelligence, and so on.

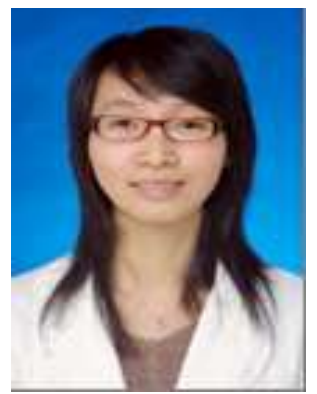

Yuyan Luo is a doctoral student in Sichuan University for majoring in management science and engineering, and a member of Information and Business Management Institute of Sichuan University. Her researches mainly relate to system engineering and modeling, system and information science, industrial engineering and evaluation technology, etc. She has taken part in about ten projects as a main researcher. In recent years, she has published about ten academic papers, some of which are retrieved by SCI, EI or CSSCI. 